Title:

\title{
Vision 2020: Where are We?
}

\section{Corresponding Author:}

Rupert Bourne BSc FRCOphth MD

Glaucoma Service, Cambridge University Hospital, Hills Rd, Cambridge CB2 0QQ UK

+447931541295

No fax

rb@rupertbourne.co.uk

Affiliation:

1. Glaucoma Service, Cambridge University Hospital, Cambridge, UK

2. Vision \& Eye Research Institute, School of Medicine, Anglia Ruskin University, Cambridge, UK

I have no conflicts of interest in relation to this article

\section{Purpose of review:}

To describe the VISION 2020: The Right to Sight, global initiative for the elimination of avoidable blindness, the contribution of glaucoma to the magnitude of global blindness and priorities going forward.

Recent findings: Although the target of the World Health Organization's Global Action Plan (2014-2019) has not been met in terms of $25 \%$ reduction in avoidable blindness, there is evidence that the contribution of glaucoma to blindness and vision impairment is reducing. Yet this focus on a threshold of visual acuity by which to 
measure prevalence underestimates the true burden of glaucoma. Recent population-based studies demonstrate the scale of the unmet need.

Summary: Scaling up of integrated people-centred eye care, by embedding glaucoma detection and care pathways in health systems with a strong focus on primary health care, is necessary. Solutions include reinforcing existing pathways while emphasising high quality glaucoma care, in addition to novel solutions such as self-testing, digital portable technology, artificial intelligence, and multi-level care pathways that extend to the most underserved parts of the global community.

Keywords: glaucoma, epidemiology, blindness

\section{Introduction:}

VISION 2020: The Right to Sight, the joint global initiative for the elimination of avoidable blindness of $\mathrm{WHO}$ and the International Agency for the Prevention of Blindness, has been important in increasing awareness of avoidable blindness and has resulted in the establishment of regional and national entities that facilitate a broad range of activities. ${ }^{1}$ The adoption of resolution WHA66.4 entitled Towards universal eye health: a global action plan 2014-2019 by the Sixty-sixth World Health Assembly opened up a new opportunity for Member States to progress with their efforts to prevent visual impairment and strengthen rehabilitation of the blind in their communities. As the period of the World Health Organization's Global Action Plan (2014-2019) comes to an end, there is recognition that its target of a $25 \%$ reduction in avoidable blindness has not yet been met owing largely to the aging of populations. ${ }^{2}$

\section{Text of review:}

As countries move up the spectrum of development, more people live into adulthood, the average age of the population increases and the disease burden shifts to noncommunicable diseases and disabilities. Glaucoma, a disease with a strong association with ageing, is a classic example of the effects of this 'epidemiological transition' ${ }^{3}$ The purpose of this review is to identify some of the recent key developments in our knowledge of the epidemiology of glaucoma and its relevance for the advocacy efforts that VISION 2020 promoted. 
One of the metrics for measuring health burden is Years Lived with Disability (YLD). In 2018, the Global Burden of Disease Study estimated that in 2017, prevalent glaucoma causing blindness or vision impairment accounted for 5.99 million (95\% uncertainty interval (UI): 5.17 .5 to 6.98$)$ YLDs. ${ }^{4}$ The age-standardised rate had decreased significantly by $6.0 \%$ (95\% UI,-7.4 to -4.2) between 1990 and 2007, and by $4.7 \%$ (95\% UI, -5.8 to -3.6 ) between 2007 and 2017 . These findings from a global statistical model involving cross-sectional data from many population-based studies confirms the long-term reduction in glaucoma blindness incidence noted by the very few studies that have measured this. ${ }^{5}$ In terms of its overall contribution to blindness, a series of regional reports estimate glaucoma's contribution to blindness in 2015 to range between $6 \%$ (South Asia) to 16\% (Sub-Saharan Africa), while for vision impairment (<6/18 to $3 / 60$ presenting visual acuity in the better eye), its contribution ranged between $1 \%$ (South Asia) to $4 \%$ (Sub-Saharan Africa). ${ }^{6-11}$ It is important to note that these models consider only the cases of glaucoma that reduce visual acuity below $6 / 18$ in the better eye with no consideration given to severity of visual field loss in the definition. Therefore these estimates very much underestimate the full 'burden' of disability or impact on quality of life caused by glaucoma.

Recent population-based surveys, such as the National Eye Health Survey in Australia estimated the actual prevalence of glaucoma (irrespective of visual acuity) in non-indigenous participants to be $1.8 \%$ in those $<60$ years, $3.0 \%$ in those aged $60-69$ years, $4.2 \%$ in those aged $70-79$ years and $6.7 \%$ in those aged $\geq 80$ years. ${ }^{12}$ While in indigenous Australians, the prevalence was lower. Nearly half of nonIndigenous participants and more than $70 \%$ of Indigenous participants with glaucoma did not have a known history of the disease. These low rates of detected glaucoma are not dissimilar to those reported in the past in other high-income countries such as Greece ${ }^{13}$ or the USA. ${ }^{14} \mathrm{~A}$ recent systematic review also makes the important point of how little is known of the prevalence and causes of vision loss in the indigenous peoples of the World, most of which is avoidable. ${ }^{15}$

China must present one of the most rapidly changing populations in terms of demographics. A recent analysis from multiple in-country population-based studies estimated 13.12 million people $(95 \% \mathrm{Cl}=9.88-17.68)$ to be affected in 2015 , with more than half (54\%) being Primary Angle Closure glaucoma cases. Urbanicity was 
a risk factor after controlling for age and gender. By 2050 the authors estimate 25 million people in China will be affected by glaucoma. ${ }^{16}$ Additionally in Singapore Chinese, a recent study estimates the number of people affected by glaucoma to also double (between 2015 and 2040). ${ }^{17}$

The setting of targets was only one part of the Vision 2020 initiative. The impact that it has had in establishing regional and national entities, often with national Action Plans has been very significant and there is no doubt that this has promoted increasing awareness of avoidable blindness by both governments and nongovernmental organisations. Most countries now have glaucoma professional organizations and super-national bodies such as the World Glaucoma Association have been successful in raising the profile of glaucoma. ${ }^{18}$ Addressing the existing burden of glaucoma and implementation of prevention strategies for glaucoma will always be more complicated than for example cataract, where most countries have increased their cataract surgical rate. However, just as was experienced with the early decades of increased cataract surgery, the quality of glaucoma care is just as important as quantity. Screening must be cost-effective and sustainable and this may be possible in some populations ${ }^{19}$ yet in most areas of the World there is a reliance on opportunistic case detection. Efforts to increase awareness of glaucoma in primary care and in existing eyecare programs such as cataract and diabetic retinopathy screening need to be heightened.

Modifications in our treatment options for newly diagnosed glaucoma based on recently published evidence may have significant ramifications in low and middle income countries. ${ }^{20} 21$ For example in Africa, where there are many barriers to the uptake of glaucoma treatment such as availability, accessibility, and affordability of treatments, ${ }^{22}$ as well as the expense of surgical treatment, selective laser trabeculoplasty has been shown to be a favorable alternative to medical or surgical care, being highly effective and safe in people of African descent. ${ }^{23} 24$

Linking the detection of glaucoma with other healthcare case detection programs, self-testing, digital portable technology, ${ }^{25}$ artificial intelligence solutions, ${ }^{26}$ telemedicine ${ }^{27}$ and multi-level care pathways that extend to the most peripheral communities, offers the opportunity to reach the substantial proportion of people who 
remain undiagnosed and who are at significant risk of impaired quality of life with or without vision impairment.

\section{Conclusion:}

The World Health Organisation published its first World Report on Vision in October 2019. ${ }^{28}$ The theme of the report is to support integrated people-centred eye care, embedded in health systems and based on strong primary health care, and to scale it up widely. This approach is particularly important for glaucoma with the significant advances we have seen recently in the detection and treatment of glaucoma in clinic populations yet there is a need to address the unmet need at the population level.

\section{Bullet point sentences (5)}

1. There is evidence that the contribution of glaucoma to blindness and vision impairment is reducing yet the numbers of people with vision loss due to glaucoma is increasing due to increasing age of populations.

2. The focus on visual acuity thresholds used in blindness/vision impairment prevention strategies means that the true burden of glaucoma is underestimated.

3. Awareness of glaucoma among the public even in high income countries remains low and population-based studies of glaucoma confirm that the majority of people with glaucoma remain undiagnosed.

4. While glaucoma case detection remains largely opportunistic, efforts to increase awareness of glaucoma in primary care and in existing eyecare programs such as cataract and diabetic retinopathy screening need to be heightened.

5. Novel technologies, such as telemedicine and deep learning, that can be applied to the diagnosis and monitoring of patients with glaucoma offer the opportunity to scale up the delivery and efficacy of glaucoma care. 


\section{References:}

1. VISION 2020: The Right to Sight. http://www.iapb.org/vision-2020, accessed 16.10.19

2. Ackland $P$, Resnikoff $S$, Bourne R. World blindness and visual impairment: despite many successes, the problem is growing. Community Eye Health. 2017;30(100):71-73.

3. Omran, A. R. The epidemiological transition: A theory of the epidemiology of population change. "The Milbank Quarterly. 197183 (4): 731-57.

4. GBD 2017 Disease and Injury Incidence and Prevalence Collaborators. Global, regional, and national incidence, prevalence, and years lived with disability for 354 diseases and injuries for 195 countries and territories, 1990-2017: a systematic analysis for the Global Burden of Disease Study 2017. Lancet. 2018 Nov 10;392(10159):1789-1858.

5. Malihi M, Moura Filho ER, Hodge DO, Sit AJ. Long-term trends in glaucomarelated blindness in Olmsted County, Minnesota.

Ophthalmology. 2014 Jan;121(1):134-141

6. Nangia V, Jonas JB, George R, Lingam V, Ellwein L, Cicinelli MV, Das A, Flaxman SR, Keeffe JE, Kempen JH, Leasher J, Limburg H, Naidoo K, Pesudovs K, Resnikoff S, Silvester AJ, Tahhan N, Taylor HR, Wong TY, Bourne RRA, Vision Loss Expert Group of the Global Burden of Disease Study. Prevalence and causes of blindness and vision impairment: magnitude, temporal trends and projections in South and Central Asia. $\mathrm{Br} \mathrm{J}$ Ophthalmol. 2019 Jul;103(7):871-877

7. Prevalence and causes of vision loss in South-east Asia and Oceania in 2015: magnitude, temporal trends and projections. Keeffe JE, Casson RJ, Pesudovs K, Taylor HR, Cicinelli MV, Das A, Flaxman SR, Jonas JB, Kempen JH, Leasher J, Limburg H, Naidoo K, Silvester AJ, Stevens GA, Tahhan N, Wong TY, Resnikoff S, Bourne RRA. Br J Ophthalmol. 2018 Sep 12.

8. Prevalence and causes of vision loss in Latin America and the Caribbean in 2015: magnitude, temporal trends and projections. Leasher JL, Braithwaite T, 
Furtado JM, Flaxman SR, Lansingh VC, Silva JC, Resnikoff S, Taylor HR, Bourne RRA; Vision Loss Expert Group of the Global Burden of Disease Study. Br J Ophthalmol. 2018 Sep 12.

9. Prevalence and causes of vision loss in North Africa and Middle East in 2015: magnitude, temporal trends and projections. Kahloun R, Khairallah M, Resnikoff S, Cicinelli MV, Flaxman SR, Das A, Jonas JB, Keeffe JE, Kempen JH, Leasher J, Limburg H, Naidoo K, Pesudovs K, Silvester AJ, Tahhan N, Taylor HR, Wong TY, Bourne RRA. Br J Ophthalmol. 2018 Sep 12.

10. Prevalence and causes of vision loss in high-income countries and in Eastern and Central Europe in 2015: magnitude, temporal trends and projections. Bourne RRA, Jonas JB, Bron AM, Cicinelli MV, Das A, Flaxman SR, Friedman DS, Keeffe JE, Kempen JH, Leasher J, Limburg H, Naidoo K, Pesudovs K, Peto T, Saadine J, Silvester AJ, Tahhan N, Taylor HR, Varma R, Wong TY, Resnikoff S; Vision Loss Expert Group of the Global Burden of Disease Study. Br J Ophthalmol. 2018 May;102(5):575-585

11. Cheng CY, Wang N, Wong TY, Congdon N, He M, Wang YX, Braithwaite T, Casson RJ, Cicinelli MV, Das A, Flaxman SR, Jonas JB, Keeffe JE, Kempen JH, Leasher J, Limburg H, Naidoo K, Pesudovs K, Resnikoff S, Silvester AJ, Tahhan N, Taylor HR, Bourne RRA; Vision Loss Expert Group of the Global Burden of Disease Study. Prevalence and causes of vision loss in East Asia in 2015: magnitude, temporal trends and projections. $\mathrm{Br} \mathrm{J}$ Ophthalmol. 2019 Aug 28.

12. Keel S, Xie J, Foreman J, Lee PY, Alwan M, Fahy ET, van Wijngaarden P,1,2 Gaskin JCF, Ang GS, Crowston JG, Taylor HR, Dirani M. Prevalence of glaucoma in the Australian National Eye Health Survey. Br J Ophthalmol 2019;103:191-195.*

[Only $52 \%$ of non-Indigenous Australians and $28 \%$ of Indigenous Australians with glaucoma selfreported a known history of glaucoma]

13. Topouzis $F^{1}$, Coleman AL, Harris A, Koskosas A, Founti P, Gong G, Yu F, Anastasopoulos E, Pappas T, Wilson MR. Factors associated with undiagnosed open-angle glaucoma: the Thessaloniki Eye Study. Am J Ophthalmol. 2008 Feb;145(2):327-335

14. Shaikh Y, Yu F, Coleman AL. Burden of undetected and untreated glaucoma in the United States. Am J Ophthalmol. 2014 Dec;158(6):1121-1129. 
15. Foreman J, Keel S, van Wijngaarden P, Bourne RA, Wormald R, Crowston J, Taylor HR, Dirani M. Prevalence and Causes of Visual Loss Among the Indigenous Peoples of the World: A Systematic Review. JAMA Ophthalmol. 2018 May 1;136(5):567-580

16. Song P, Wang J, Bucan K, Theodoratou E, Rudan I, Chan KY. National and subnational prevalence and burden of glaucoma in China: A systematic analysis. J Glob Health. 2017 Dec;7(2):020705.

17. Ansah JP, Koh V, de Korne DF, Bayer S, Pan C, Thiyagarajan J, Matchar DB, Lamoureux E, Quek D. Projection of Eye Disease Burden in Singapore. Ann Acad Med Singapore. 2018 Jan;47(1):13-28.

18. World Glaucoma Week 2019. World Glaucoma Association. https://wga.one/wga/world-glaucoma-week/ (accessed 16 October 2019). 19. Tang J, Liang Y, O'Neill C, Kee F, Jiang J, Congdon N. Cost-effectiveness and cost-utility of population-based glaucoma screening in China: a decisionanalytic Markov model. Lancet Glob Health. 2019 Jul;7(7):e968-e978.**

[Markov models used to estimate cost-effectiveness and cost-utility of population-level glaucoma screening for glaucoma (primary open and closed angle glaucoma combined). Using screening costs taken from a Chinese screening programme and treatment costs from a tertiary Chinese eye hospital, the authors concluded that screening is likely to be cost-effective in rural and more so in urban China.]

20. Gazzard $G^{1}$, Konstantakopoulou $E^{2}$, Garway-Heath $D^{2}$, Garg $A^{2}$, Vickerstaff $\mathrm{V}^{3}$, Hunter $\mathrm{R}^{4}$, Ambler $\mathrm{G}^{5}$, Bunce $\mathrm{C}^{6}$, Wormald $\mathrm{R}^{7}$, Nathwani $\mathrm{N}^{8}$, Barton $\mathrm{K}^{2}$, Rubin $\mathrm{G}^{9}$, Buszewicz M${ }^{4}$; LiGHT Trial Study Group. Selective laser trabeculoplasty versus eye drops for first-line treatment of ocular hypertension and glaucoma (LiGHT): a multicentre randomised controlled trial.

Lancet. 2019 Apr 13;393(10180):1505-1516. *

[randomised controlled trial of treatment-naive patients with open angle glaucoma or ocular hypertension randomised to initial selective laser trabeculoplasty (SLT) or to eye drop, and followed for 3 years. At 3 years, there was no difference in quality of life observed between groups and $74 \%$ of patients in the SLT group required no drops to maintain intraocular pressure at target. SLT was a cost-effective alternative to eye drops and offering SLT as a first-line treatment was recommended]

21. Ang GS ${ }^{\# 1}$, Fenwick $E K^{\# 2,3,4}$, Constantinou $M^{3}$, Gan $A^{2} L^{2}$, Man $R E K^{2}$, Casson $\mathrm{RJ}^{5}$, Finkelstein $\mathrm{EA}^{4}$, Goldberg $\mathrm{I}^{6}$, Healey $\mathrm{PR}^{6,7}$, Pesudovs $\mathrm{K}^{8,9}$, Sanmugasundram $\mathrm{S}^{3}$, Xie $\mathrm{J}^{3}$, Mclntosh $\mathrm{R}^{3}$, Jackson $\mathrm{J}^{10,11}$, Wells $A P^{12}$, White $A^{6,7,13}$, Martin $\mathrm{K}^{1,3,14,15}$, Walland $\mathrm{MJ}^{1}$, Crowston $J^{2,3,4,15}$, Lamoureux $\mathrm{EL}^{16,3,4}$. Selective laser trabeculoplasty versus topical 
medication as initial glaucoma treatment: the glaucoma initial treatment study randomised clinical trial. $\mathrm{Br} \mathrm{J}$ Ophthalmol. 2019 Sep 5.

22. Smith $A F^{1,2}$, Negretti $G^{3,4}$, Mascaro $A^{2,5}$, Bokre $D^{3}$, Baker $H^{3}$, Dhalla $\mathrm{K}^{6}$, Murdoch IE ${ }^{3,4}$. Glaucoma Control Strategies in Sub-Saharan Africa: A Review of the Clinical and Health Economic Evidence. Ophthalmic Epidemiol. 2018 Oct - Dec;25(5-6):419-435. *

[A systematic review of the effectiveness, costs, and cost-effectiveness of detection and treatment strategies for glaucoma control in Sub-Saharan Africa that concluded that while effective glaucoma control interventions exist, their widespread use and diffusion across this region remain challenging principally due to low per capita income levels and high glaucoma treatment costs.]

23. Realini $T^{1}$, Shillingford-Ricketts $\mathrm{H}^{2}$, Burt $\mathrm{D}^{3}$, Balasubramani $\mathrm{GK}^{4}$. West Indies Glaucoma Laser Study (WIGLS)-2: Predictors of Selective Laser Trabeculoplasty Efficacy in Afro-Caribbeans With Glaucoma. J Glaucoma. 2018 Oct;27(10):845-848.

24. Realini $\mathrm{T}^{1}$, Olawoye $\mathrm{O}^{2}$, Kizor-Akaraiwe $\mathrm{N}^{3}$, Manji $\mathrm{S}^{4}$, Sit $\mathrm{A}^{5}$. The Rationale for Selective Laser Trabeculoplasty in Africa. Asia Pac J Ophthalmol (Phila). 2018 Nov-Dec;7(6):387-393. *

25. Jones PR, Smith ND, Bi W, Crabb DP. Portable Perimetry Using EyeTracking on a Tablet Computer-A Feasibility Assessment. Transl Vis Sci Technol. 2019 Feb 5;8(1):17.

26. Ting DSW, Peng L, Varadarajan AV, Keane PA, Burlina PM, Chiang MF, Schmetterer L, Pasquale LR, Bressler NM, Webster DR, Abramoff M, Wong TY. Deep learning in ophthalmology: The technical and clinical considerations. Prog Retin Eye Res. 2019 Sep;72:100759.

27. Hark $L A^{1,2}$, Radakrishnan $A^{3}$, Madhava $M^{3}$, Anderson-Quiñones $\mathrm{C}^{1,3}$, Fudemberg $\mathrm{S}^{1,3}$, Robinson $\mathrm{D}^{1}$, Myers $\mathrm{JS}^{1,3}$, Zhan $\mathrm{T}^{4}$, Adeghate $\mathrm{J}^{5}$, Hegarty $\mathrm{S}^{4}$, Leite $\mathrm{S}^{1}$, Leiby $\mathrm{BE}^{4}$, Stempel $\mathrm{S}^{2}$, Katz $\mathrm{LJ}^{1,3}$. Awareness of ocular diagnosis, transportation means, and barriers to ophthalmology followup in the Philadelphia Telemedicine Glaucoma Detection and Follow-up Study. Soc Work Health Care. 2019 Aug;58(7):651-664. *

[this study assessed factors affecting follow-up eye care in participants enrolled in the Philadelphia Telemedicine Glaucoma Detection and Follow-up Study. Among several factors investigated, $30 \%$ of participants were unaware of or did not comprehend the severity of their ocular diagnosis, highlighting the importance of additional assistance and improved explanation to patients where there is a risk to adherence to follow-up care] 
28. World report on vision. World Health Organization.

https://www.who.int/publications-detail/world-report-on-vision (accessed 16 October 2019).

\section{Acknowledgements}

None

Financial support and sponsorship

None relevant to this work

\section{Conflicts of interest}

None relevant to this work 